\title{
Hedgehog signalling promotes germ cell survival in the rat testis
}

\author{
Juho-Antti Mäkelä1,5, Vuokko Saario ${ }^{1}$, Sonia Bourguiba-Hachemi ${ }^{1}$, Mirja Nurmio ${ }^{1,2}$, \\ Kirsi Jahnukainen ${ }^{3,4}$, Martti Parvinen ${ }^{1}$ and Jorma Toppari ${ }^{1,2}$ \\ Departments of ${ }^{1}$ Physiology and ${ }^{2}$ Paediatrics, University of Turku, FIN-20520 Turku, Finland, ${ }^{3}$ Division of \\ Hematology-Oncology and Stem Cell Transplantation, Hospital for Children and Adolescents, University of Helsinki, \\ FIN-00029 Helsinki, Finland, ${ }^{4}$ Department of Woman and Child Health, Karolinska Institute and University Hospital, \\ SE-171 76 Stockholm, Sweden and ${ }^{5}$ Turku Graduate School of Biomedical Sciences, University of Turku, Turku, \\ Finland
}

Correspondence should be addressed to J-A Mäkelä at Department of Physiology, University of Turku; Email: juho-antti.makela@utu.fi

\begin{abstract}
Hedgehog (Hh) signalling has a crucial role in testis development. Sertoli cell-derived desert hedgehog (DHH) guides the formation of testis cords and differentiation of foetal-type Leydig cells. Dhh mutant mice are infertile due to a block in germ cell differentiation, hypogonadism and hypoandrogenism. Hh signalling pathway components are also expressed in postnatal testis. In the rat testis the transcription factor of the Hh pathway, glioma-associated oncogene homologue (GLI1), is expressed by a wide variety of germ cells. This suggests that $\mathrm{Hh}$ signalling is involved in spermatogenesis at many different levels. Our data show that canonical Hh signalling is turned off in early condensing spermatids that strongly express the negative regulator of the pathway, suppressor of fused (SUFU). Most of the Hh pathway specific mRNAs display the highest values in stages II-VI of the rat seminiferous epithelial cycle. The key endocrine regulator of germ cell differentiation, FSH, down-regulates Dhh mRNA levels in vitro. Hh signalling inhibition in vitro leads to massive apoptosis of germ cells. In prepubertal rat testis imatinib mesylate-induced inhibition of tyrosine kinases impinges on Dhh transcript levels and Hh signalling. Our data indicate that $\mathrm{Hh}$ signalling is part of the paracrine signalling network in the rat testis. It promotes the survival of germ cells and is suppressed by FSH.
\end{abstract}

Reproduction (2011) $142711-721$

\section{Introduction}

Desert hedgehog $(\mathrm{DHH})$, the testis-specific member of mammalian hedgehog $(\mathrm{Hh})$ protein family, is one of the first genes to be expressed in the developing male gonad (Bitgood et al. 1996). Blocking $\mathrm{Hh}$ signalling in the developing testis genetically or pharmacologically leads to severe disruption in testicular histology resulting in spermatogenic defects and infertility (Clark et al. 2000, Pierucci-Alves et al. 2001, Yao \& Capel 2002). In addition to the disorganised seminiferous epithelium, disrupted spermatogenesis may partly be due to low androgen levels since $\mathrm{Hh}$ signalling is needed for the differentiation of foetal Leydig cells (Yao et al. 2002, Barsoum et al. 2009) and to maintain the expression of steroidogenic enzymes (Brokken et al. 2009). Regulation of the Hh pathway in the testis is poorly understood but recent data suggest that environmental factors can interfere with it. Fowler et al. (2008) reported that maternal smoking during pregnancy impinges on $\mathrm{DHH}$ mRNA levels during testis development in utero. Our previous results demonstrate that the antiandrogen flutamide down-regulates the mRNA levels of $\mathrm{Hh}$ pathway genes (Brokken et al. 2009).

The role of $\mathrm{Hh}$ signalling in spermatogenesis has remained unknown until recently. In the mouse, Sertoli cell-derived DHH binds patched (PTCH) receptor on the surface of primary spermatocytes relieving smoothened (SMO) repression and activating glioma-associated oncogene homologue (GLI) transcription factors (Bitgood et al. 1996, Carpenter et al. 1998, Taipale et al. 2002). Gli1 and Ptch1 are among the first genes whose transcription is triggered in response to the activation of Hh signalling pathway (Hooper \& Scott 1989, Lee et al. 1997). In a recent study, Morales et al. (2009) confirmed and redefined these findings in another rodent model, the rat, by showing that $\mathrm{DHH}$ is produced in Sertoli cells, whereas meiotic and post-meiotic cells stained positively for PTCH1 and SMO. Interestingly, they also demonstrated that late primary spermatocytes, secondary spermatocytes, round spermatids and Leydig cells express PTCH1 in the adult mouse testis. This would suggest that $\mathrm{DHH} / \mathrm{PTCH} 1$ signalling takes part in control 
of meiotic divisions and adult-type Leydig cell function. However, it is also highly contradictory to what has been shown previously by Carpenter et al. (1998). They indicated that Ptch2 is the only $\mathrm{Hh}$ receptor that is highly expressed in adult mouse testis. In situ hybridisation revealed that Ptch2 is strongly expressed in seminiferous tubules, whereas only a weak expression of Ptch1 can be observed in the interstitium. Besides meiosis Hh signalling is probably active also in spermatogonia that express the genes of the pathway (Szczepny et al. 2006). However, when seminiferous tubule segments were cultured in hanging drops in the presence of $\mathrm{Hh}$ signalling inhibitor, cyclopamine, no significant effects on proliferation of spermatogonia or survival of germ cells were recorded (Szczepny et al. 2009). Interestingly, $\mathrm{Hh}$ signalling inhibition was followed by lower mRNA levels of Scf and Kit (c-Kit) suggesting that it might secondarily affect survival of differentiating germ cells (Yoshinaga et al. 1991, Hakovirta et al. 1999, Yan et al. 2000a, 2000b, 2000c).

The aim of this study was to elucidate the role of $\mathrm{Hh}$ signalling in rat spermatogenesis and to compare the results with the previous findings in the mouse. Our data suggest that $\mathrm{Hh}$ signalling acts at many levels during spermatogenesis in the rat testis and shows that one of the physiological functions of $\mathrm{Hh}$ signalling is to promote germ cell survival. Inhibition of receptor tyrosine kinases (RTKs; such as KIT) in the prepubertal rat downmodulates $\mathrm{Hh}$ signalling in vivo, whereas the steadystate levels of Dhh mRNA are suppressed by FSH in adult in vitro demonstrating that testicular $\mathrm{Hh}$ signalling is under endocrine and paracrine control.

\section{Results}

\section{The transcripts of Hh signalling pathway components are present in the rat testis at all ages}

We isolated total RNA from testes of 1, 5, 10, 20, 30, 40 and 60-90-day-old rats (four animals per age group) and used it as a template in qRT-PCR to study if the mRNAs of Hh pathway genes are present in the postnatal rat testis. Transcripts of all the genes that we studied (Dhh, Ptch1, Ptch2, Gli1, Gli2, Gli3 and suppressor of fused (Sufu)) were detected at every time point (Fig. 1). Three different patterns were observed: Dhh, Ptch1, Gli2 and Gli3 mRNA levels increased after birth and showed the highest values prepubertally and steadily decreased thereafter (Fig. 1A and B); the steady-state level of Gli1 transcript started to decline steadily after birth (Fig. 1B); Sufu mRNA was present at a very low level in young rat testis but its steady-state level increased markedly after puberty (Fig. 1B). The level of Ptch2 transcript did not change significantly over time (Fig. 1A). Statistical significances were tested using one-way ANOVA and are reported against the data point of the highest value in Fig. 1. To normalise the Dhh transcript level to Sertoli
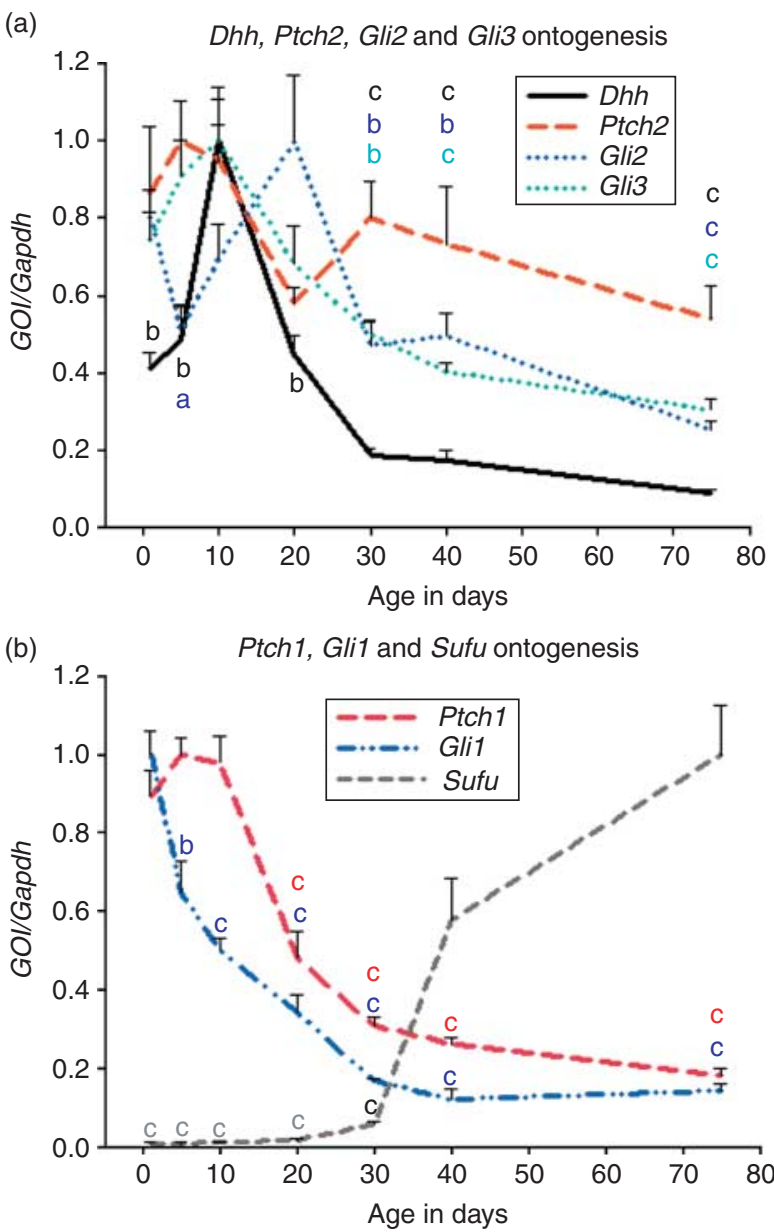

(c) Dhh ontogenesis normalized to Sertoli cell number

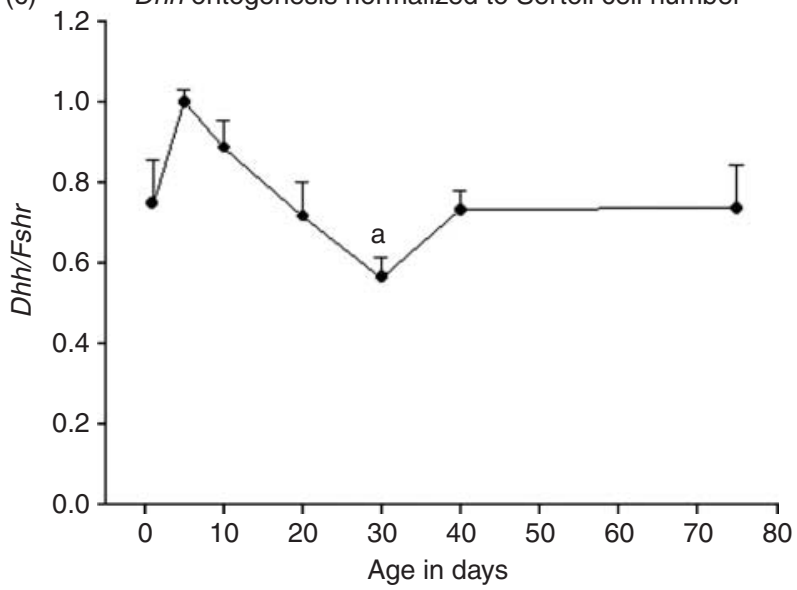

Figure 1 Age-dependent steady-state levels of Hedgehog pathway mRNAs in the rat testis. (A and B) Dhh, Ptch1, Gli2 and Gli3 mRNAs are at their highest level in prepubertal rat testis. Gli1 levels steadily decrease after birth. Until day 30 Sufu transcript is present at a very low level. Ptch2 mRNA level does not change within this time window. (C) Dhh levels show only slight changes when normalised to Sertoli cell number (Fshr mRNA level). Statistical significances were tested using ANOVA and they are marked here against the data point of the highest value. GOI, gene of interest; $n=4$, S.E.M.; ${ }^{\mathrm{a}} P<0.05$; ${ }^{\mathrm{b}} P<0.01$;

${ }^{\mathrm{c}} P<0.001$; letters $\mathrm{a}, \mathrm{b}$ and $\mathrm{c}$ on top of the error bars are in different colours based on the colour of the line marking the gene. 
cell number, relative mRNA level of FSH receptor ( Fshr) was studied. Fshr is expressed exclusively by Sertoli cells in the rat testis (Heckert \& Griswold 1991). Dhh level stayed quite constant in the Sertoli cells as the rat grew older, the only significant difference being between postnatal days 5 and 30 (Fig. 1C). Sonic hedgehog and Indian hedgehog transcripts were not present in the rat testis (data not shown).

\section{Immunohistochemical staining of Hh pathway proteins in mature rat testis}

In accordance with mRNA level findings, the negative regulator of the pathway, SUFU, was located only in early condensing spermatids in the rat testis (Fig. 2A and B). Developmentally we could first locate SUFU in spermatids of 40-day-old rats (Fig. 2A). In adult, SUFU protein expression was first observed in step 9 (stage IX) condensing spermatids. The signal was strongest in steps 10-13 (stages X-XIII) spermatids and became weaker towards stage I (Fig. 2B). SUFU was no longer expressed in steps 15-18 (stages I-VI) condensing spermatids. Interestingly, as shown in Fig. $2 \mathrm{C}$ and $\mathrm{D}$ (which are two consecutive sections), the expression of GLI1 in elongating spermatids was quite the opposite: cytoplasm of steps 16-18 (stages II-VI) spermatids stained strongly for GLI1, whereas no signal for GLI1 was observed in steps 9-14 (stages IX-XIV) spermatids.
These data suggest that $\mathrm{Hh}$ signalling is involved in spermiogenesis, too. In steps 9-14 spermatids (stages IX-XIV) Hh signalling is turned off by SUFU that sequesters GLI1 in the cytoplasm (Kogerman et al. 1999). Disappearance of SUFU in steps 15-18 (stages I-VI) spermatids allows GLI1 to be reactivated in the late steps of spermiogenesis.

GLI1 expression was observed at three different levels: spermatogonia, spermatocytes and late elongating spermatids (Fig. 2D and E). Spermatogonial expression of GLI1 was observed quite uniformly in all stages, whereas the staining intensity of GLI 1 in stages II-VI pachytene spermatocytes was stronger than in other stages. Primary spermatocytes also expressed PTCH1 (Fig. 2F). Zygotene spermatocytes weakly expressed the protein and immunopositivity increased towards stage VIII pachytene spermatocytes whereafter PTCH1 was no longer detectable. The meiotic and post-meiotic cell type-specific expression pattern of SUFU, GLI1 and $\mathrm{PTCH} 1$ proteins is summarised in Fig. 3.

\section{Steady-state levels of Hh signalling pathway mRNAs are spermatogenic stage-dependent}

Rat spermatogenesis is divided into 14 defined stages, I-XIV (Leblond \& Clermont 1952). We used transillumination-assisted microdissection method to cut the seminiferous tubule of five adult rats to segments

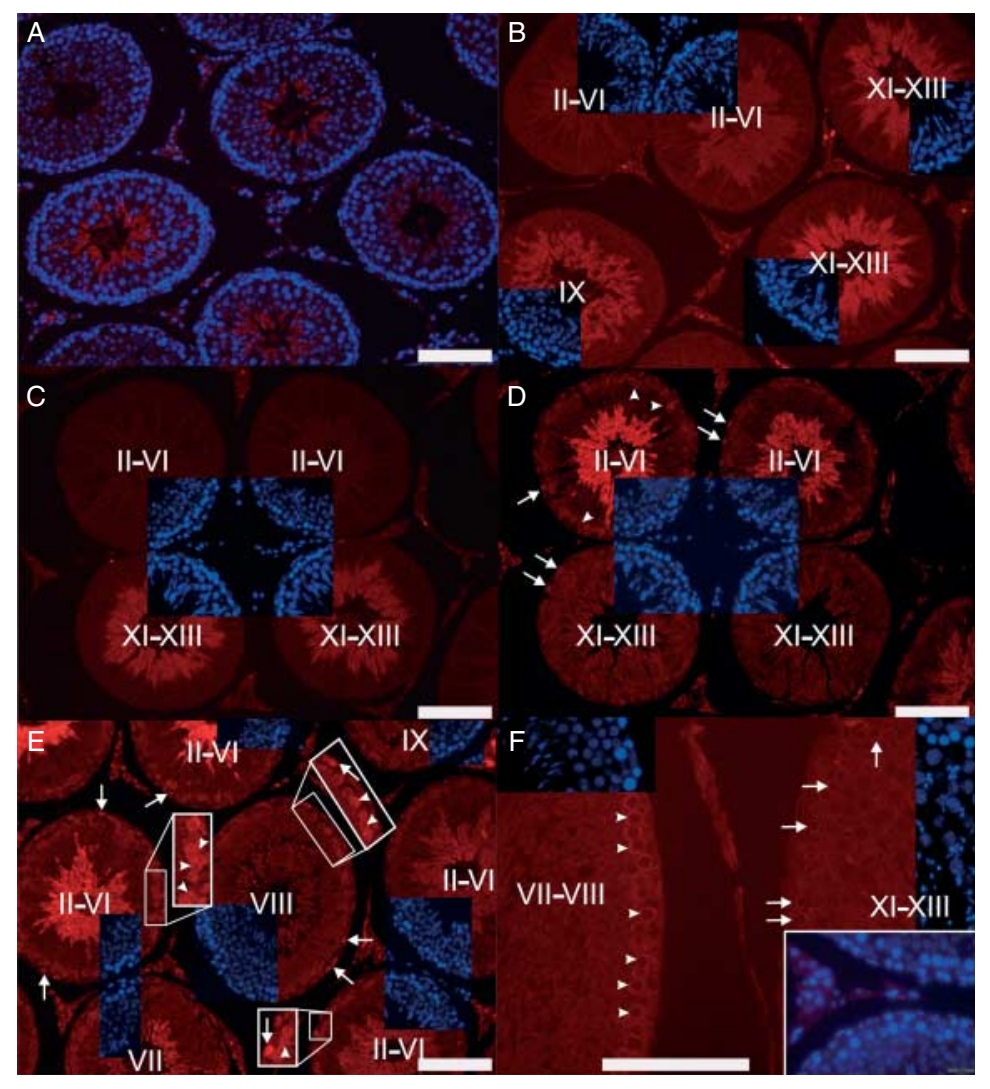

www.reproduction-online.org
Figure 2 Expression of SUFU, GLI1 and PTCH1 in mature rat testis. (A) SUFU expression (red) is first observed in 40-dayold rat in elongating spermatids. (B) In the adult rat testis, the expression starts in step 9 spermatids (stage IX) and stays at a high level till steps 12-13 spermatids (stages XII and XIII). Protein expression is down-regulated thereafter and steps 15-19 spermatids cease to express SUFU (red). (C and D) Two consecutive sections showing that the expression of SUFU (red) (C) and GLI1 (red) (D) are opposite in elongating spermatids, i.e. SUFU is expressed in steps 9-13 spermatids, whereas GLI1 is expressed in steps 16-18 spermatids. (D and E) GLI1 (red) displays a nuclear expression in spermatogonia (arrows) and nuclear/cytoplasmic expression in spermatocytes (arrowheads) while the cytoplasm of steps 16-18 spermatids stains positively for GLI1 (red). Note that stages II-VI pachytene spermatocytes stain more strongly than other primary spermatocytes. (F) Primary spermatocytes stain positively for PTCH1 (red). Pachytene spermatocytes (arrowheads) strongly express the protein whereas a weaker signal is detected in zygotene spermatocytes (arrows). Inset: negative control showing unspecific staining in the interstitium. Cell nuclei are stained in A with DAPI (blue). In B-F DAPI staining (blue) for the same section (sectors) is included to help seminiferous epithelial cycle stage recognition. The stages of the cycle of the seminiferous epithelium are indicated with Roman numerals. Scale bar $100 \mu \mathrm{m}$. 


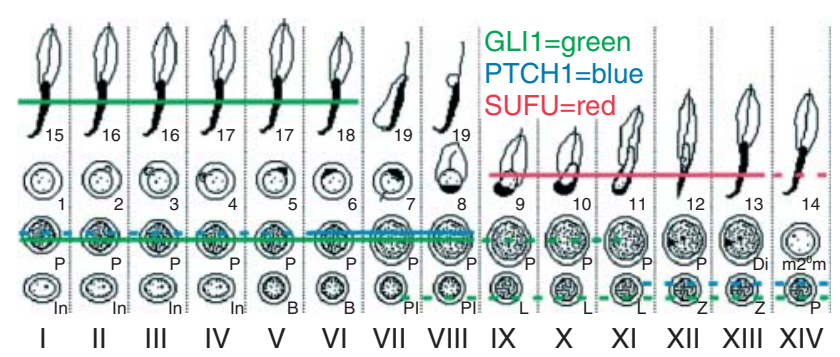

Figure 3 Schematic illustration of the SUFU, GLI1 and PTCH1 protein expression in the meiotic and post-meiotic cells of the rat seminiferous epithelial cycle. GLI1 expression is first observed in preleptotene spermatocytes and the strongest immunostaining is observed in stages II-VI pachytene spermatocytes. Thereafter, the expression is downregulated but it reappears in steps 15-18 spermatids. PTCH1 expression ranges from zygotene to stage VIII pachytene spermatocytes. SUFU localises specifically to steps 9-14 spermatids. Solid lines mark the cell types with the strongest signal in immunohistochemical staining, whereas the dotted lines show the cell types where the protein is expressed at a lower level. The specific cell associations in the vertical columns represent specific stages (Roman numerals) of the rat seminiferous epithelial cycle. Arabic numerals refer to different steps of post-meiotic germ cell differentiation. In, intermediate spermatogonia; $B$, type $B$ spermatogonia; $\mathrm{Pl}$, preleptotene spermatocytes; $\mathrm{L}$, leptotene spermatocytes; $Z$, zygotene spermatocytes; $P$, pachytene spermatocytes; $\mathrm{Di}$, diplotene spermatocytes; $\mathrm{m} 2^{\circ} \mathrm{m}$, meiotic divisions.

representing four pooled stages (II-VI, VII and VIII, IX-XII and $\mathrm{XIII}-\mathrm{I}$ ) of the rat seminiferous epithelial cycle. qRT-PCR analysis showed that the Dhh and Gli1 mRNA levels were at their highest in stages II-VI (Fig. 4A and B). The steady-state levels of Ptch1 mRNA were significantly higher in stages II-VIII than in stages IX-I (Fig. 4C). The mRNA level of Ptch2 was significantly lower in stages XIII-I compared with stages IX-XII (Fig. 4D). Sufu transcript was present at a very low level in stages II-VI and XIII-I, and markedly more in stages VII-XII (Fig. 4E). Statistical significances were tested using ANOVA.

\section{GLI1 is developmentally expressed in spermatogonia, meiotic and post-meiotic germ cells}

Hh signalling is most active in prepubertal rat testis according to mRNA transcript levels. Thus, we examined the localisation of GLI1 expression in PFA-fixed testicular tissue sections in 5, 10, 20, 30 and 40-dayold rats (Fig. 5A and C-F). Nuclear localisation of GLI1 was observed already in spermatogonia of 5-day-old rats (Fig. 5A) that also expressed PTCH1 (Fig. 5B). At 10, 20, 30 and 40 days of age (Fig. 5C-F) GLI1 localised to basal spermatogonia and in the more adluminally situated meiotic germ cells. In addition, cytoplasms of elongating spermatids stained positively for GLI1 in 40-day-old rats (Fig. 5F). Interestingly, all the cells that we encountered while being in the $M$ phase of the cell cycle were strongly immunopositive for GLI1 (data not shown) suggesting that at least some of the GLI1-expressing cells are mitotically active.

\section{Recombinant human FSH down-regulates the steady- state levels of Dhh mRNA in vitro}

FSH is a major regulator of germ cell differentiation and spermatogenesis. Therefore, we decided to study whether FSH affects Dhh mRNA levels in vitro. To analyse whether FSH effect on Dhh level is stage-specific and dose-dependent, we cultured segments from three distinct stages with five different concentrations of recombinant human FSH. Three individual experiments were done and within each experiment the same treatment was applied on three parallel samples. We have previously shown that FSH elevates the steady-state levels of Scf mRNA (Yan et al. 1999), which served as a positive control. FSH up-regulated $S c f$ levels in a dosedependent manner (Fig. 6A). The highest Scf mRNA levels were detected in stages II-VI, which were also stimulated both at 8 and $30 \mathrm{~h}$.

There were no significant changes in the steady-state levels of Dhh mRNA at $8 \mathrm{~h}$ after the beginning of FSH exposure. However, at $30 \mathrm{~h}$ the Dhh levels were downregulated in all three pooled stages but most remarkably in stages VII and VIII (Fig. 6B). A similar phenomenon was observed in Gdnf levels that were down-modulated specifically in stages II-VI but not in the other stages (Fig. 6C).

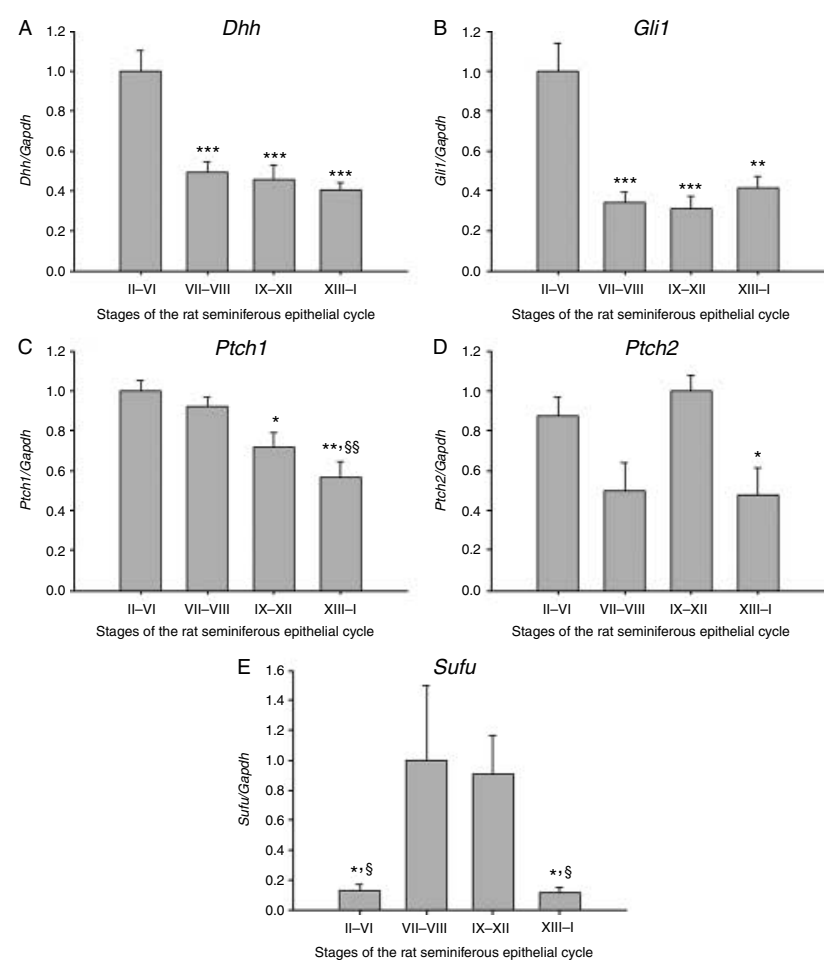

Figure 4 Steady-state levels of Hedgehog pathway mRNAs in rat seminiferous epithelial cycle. (A) Dhh and (B) Gli1 levels are high in stages II-VI compared with other stages. (C) The lowest mRNA level for Ptch1 and (D) Ptch2 is recorded in stages XIII-I. (E) Transcript levels of Sufu are high in stages VII-XII. $n=5$, S.E.M.; ${ }^{*} P<0.05 ;{ }^{*} P<0.01$; ${ }^{* * *} P<0.001$ compared with stages of the highest value. ${ }^{\S} P<0.05$; ${ }^{\S} P<0.01$ compared with stages of the second highest value. 


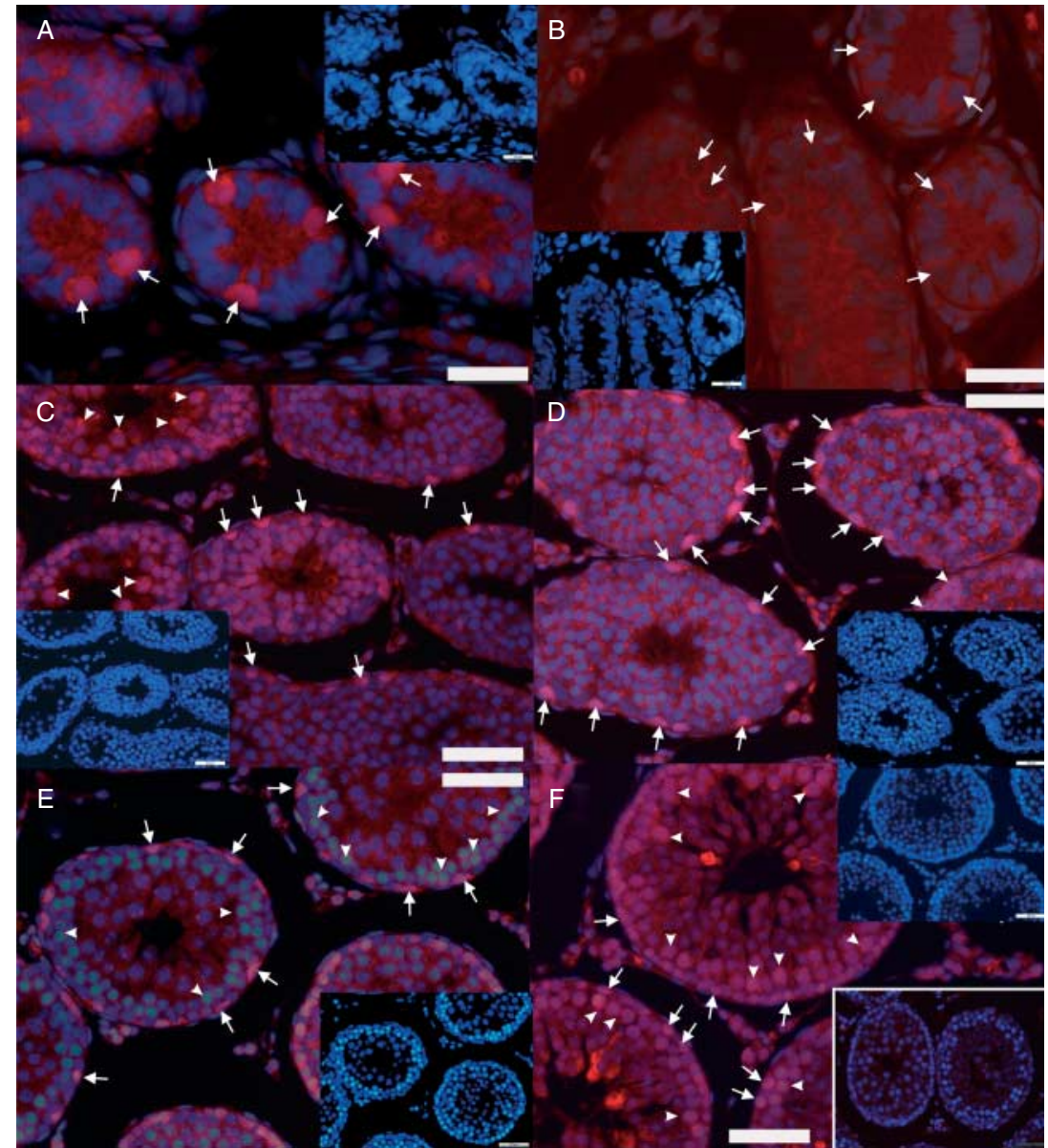

Figure 5 Developmental expression of GLI1 (red) in rat spermatogonia, spermatocytes and elongating spermatids. (A) Spermatogonia (arrows) of 5-dayold rats are immunopositive for GLI1 (red) and for (B) PTCH1 (red; arrows). Spermatogonia (arrows) and spermatocytes (arrowheads) of (C) 10, (D) 20, (E) 30 and (F) 40-day-old rats stain positively for GLI1 (red). (F) Adluminally located elongating spermatids of 40-day-old rats also express GLI1 (red). Inset: negative control. Cell nuclei are stained with DAPI (blue). Insets with smaller magnification represent the same tissue sections with DAPI staining (blue). Scale bar: (A and B) $25 \mu \mathrm{m},(\mathrm{C}-\mathrm{F}) 50 \mu \mathrm{m}$.

\section{Inhibition of Hh signalling in vitro increases apoptotic cell death of germ cells}

After seeing the highest levels of Hh pathway mRNAs in stages II-VI we decided to treat $4 \mathrm{~mm}$ long stages II-VI segments with cyclopamine, a specific inhibitor of the Hh pathway, in vitro for 8 and $16 \mathrm{~h}$. Four rats were used for this experiment. Squash preparations were made from tubule segments for immunocytochemistry to evaluate the number of cleaved caspase-3-positive apoptotic cells in specimens. Cyclopamine increased the number of apoptotic germ cells in both time points and the difference in the number of cleaved caspase-3positive cells at $16 \mathrm{~h}$ was statistically significant (Fig. 7).

\section{Imatinib mesylate dramatically represses the mRNA levels of Dhh, Ptch1 and Gli1 in prepubertal rat testis}

To pursue further the interplay of SCF/KIT, plateletderived growth factor (PDGF) and Hh signalling we decided to study whether imatinib mesylate-induced inhibition of tyrosine kinases affects the mRNA levels of Hh pathway components in vivo. Imatinib mesylate treatment had a dramatic impact on the steady-state levels of Dhh (Fig. 8A), Ptch1 and Gli1 mRNAs (Fig. 8B). Already $24 \mathrm{~h}$ after single treatment with the lower dose
$(50 \mathrm{mg} / \mathrm{kg}$ ) the relative transcript level of Dhh had decreased significantly. Down-modulation of Hh signalling due to diminished ligand production lead to decreased mRNA levels of Hh target genes Gli1 and Ptch $172 \mathrm{~h}$ after the initial exposure.

\section{Discussion}

We have elucidated the role of $\mathrm{Hh}$ signalling and its regulation in adult rat testis. We show here that $\mathrm{Hh}$ signalling promotes germ cell survival and Dhh belongs to a group of genes that are regulated by FSH in Sertoli cells in the rat testis. Imatinib-induced inhibition of RTKs interferes with $\mathrm{Hh}$ signalling, and immunohistochemical staining of Hh pathway components suggest that $\mathrm{Hh}$ signalling is activated in mitotic, meiotic and late postmeiotic germ cells and suppressed in early post-meiotic cells. Our data about the age-dependent relative abundance of $\mathrm{Hh}$ pathway mRNAs and localisation of PTCH1 and GLI1 in meiotic cells strengthen the idea that $\mathrm{Hh}$ signalling is needed in meiosis. This kind of conclusion was originally drawn by the findings of Bitgood et al. (1996) and Kroft et al. (2001). Homozygous Dhh mutation on a 129/Sv inbred background and overexpression of human GLI1 in mouse 


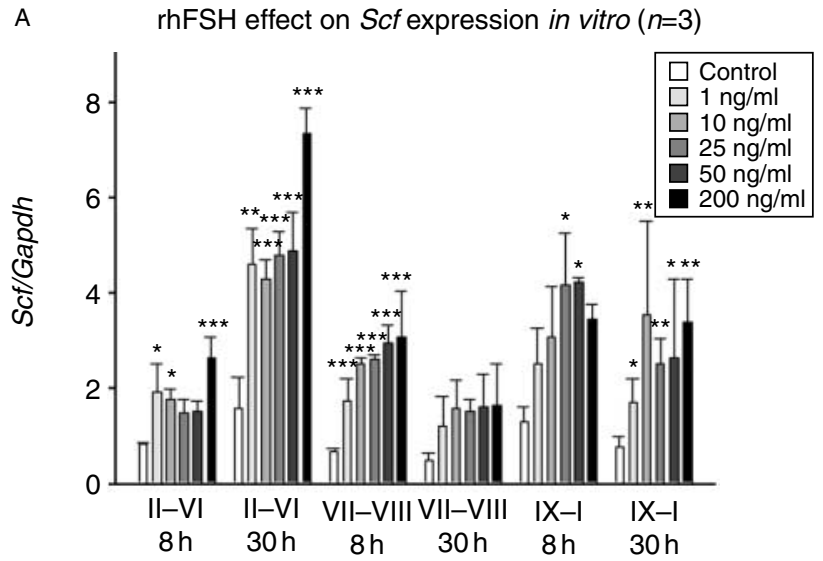

B $\quad$ rhFSH effect on Dhh expression in vitro $(n=3)$

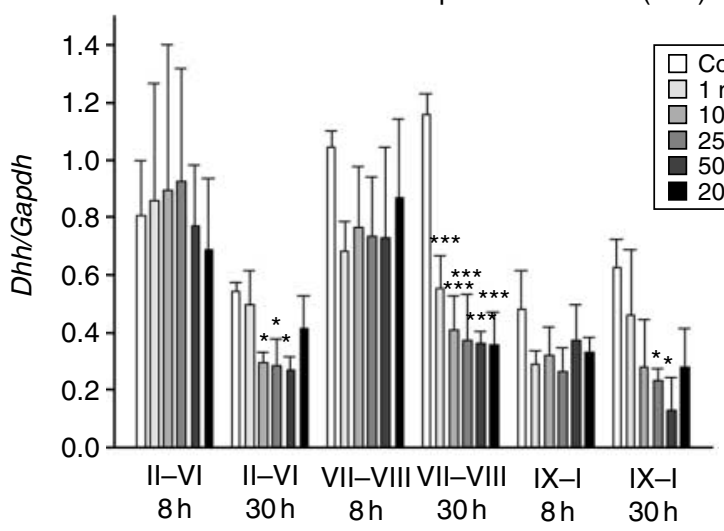

C $\quad$ rhFSH effect on Gdnf expression in vitro $(n=3)$

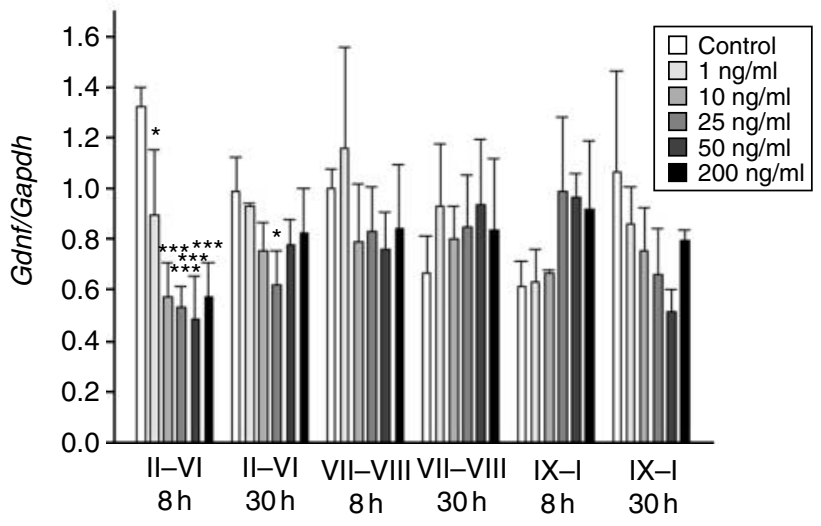

Figure 6 FSH effect on the steady-state levels of Scf, Dhh and Gdnf $\mathrm{mRNAs}$ in rat seminiferous tubules in vitro. (A) FSH up-regulates the mRNA level of $S c f$ in all stages already $8 \mathrm{~h}$ after the treatment. (B) Dhh mRNA level is down-regulated in all stages at $30 \mathrm{~h}$ after the FSH treatment. (C) Gdnf mRNA levels decline significantly specifically in stages II-VI of the rat seminiferous epithelial cycle in response to FSH treatment. $n=3$, S.E.M.; ${ }^{*} P<0.05 ;{ }^{* *} P<0.01$; ${ }^{* *} P<0.001$.

testis, respectively, leads to a halt in spermatogenesis at pachytene spermatocyte stage. These data suggest that Hh signalling needs to be down-modulated before entry into meiotic divisions. Indeed, we can see a down-regulation of Hh pathway target genes, Ptch1 and
Gli1, mRNA levels in stages IX-XIV of the rat seminiferous epithelial cycle just before the meiotic divisions. The prepubertal peak in Dhh, Ptch1, Gli2 and Gli3 mRNA levels co-occurs with the appearance of the first spermatocytes (Clermont \& Perey 1957, Malkov et al. 1998). The steady decrease in Gli1 level after birth suggests that Hh signalling is active in the rat testis even before the onset of spermatogenesis and, indeed, it has been shown to drive steroidogenesis in foetal-type Leydig cells (Barsoum et al. 2009, Brokken et al. 2009).

SUFU localises exclusively in early elongating spermatids but not in other germ cell types that suggests that canonical Hh signalling is shutdown in these cells. The relative transcript level of Sufu stays very low until day 30 and increases sharply thereafter supporting its function as a negative regulator of the Hh pathway in early condensing spermatids. According to our immunofluorescent labelling, GLI1 transcription factor is still present in the cytoplasm of late condensing spermatids. However, the existence of a functional $\mathrm{Hh}$ receptor in condensing spermatids is not yet known. Recently, more evidence on non-canonical mechanisms of GLI transcription factor activation has emerged and many signalling pathways have been shown to converge on activation of GLI transcription factors (Riobo et al. 2006, Lauth \& Toftgård 2007). Thus, it is possible that GLI1 is activated during late spermiogenesis by $\mathrm{Hh}$-independent mechanism.

The question which $\mathrm{Hh}$ receptor mediates activation of the pathway in other germ cell types deserves further attention. As mentioned in the Introduction, there are conflicting data about the role of both PTCH1 and PTCH2 in the testis. Their expression pattern both ageand stage-wise was quite different: Ptch1 shared the pattern of most other Hh pathway genes, whereas Ptch2 mRNA levels did not change much in different ages or different stages of the rat seminiferous epithelial cycle. In addition, we observed a relatively high mRNA level of Ptch1 in mouse seminiferous tubule segments (J-A Mäkelä, V Saario \& J Toppari 2011, unpublished observation) which indicates that Ptch1 transcription is not confined to the interstitium in the mouse testis either

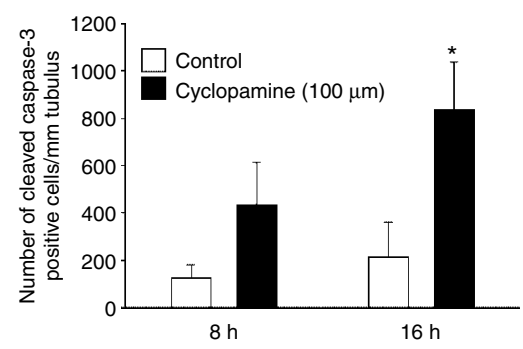

Figure 7 Effect of Hedgehog signalling inhibition on occurrence of apoptosis in rat seminiferous tubules in vitro. Cyclopamine-induced inhibition of Hedgehog signalling in vitro leads to an increase in the number of cleaved caspase-3-positive cells 8 and $16 \mathrm{~h}$ after the treatment. $n=3-4$, S.E.M.; $* P<0.05$. 

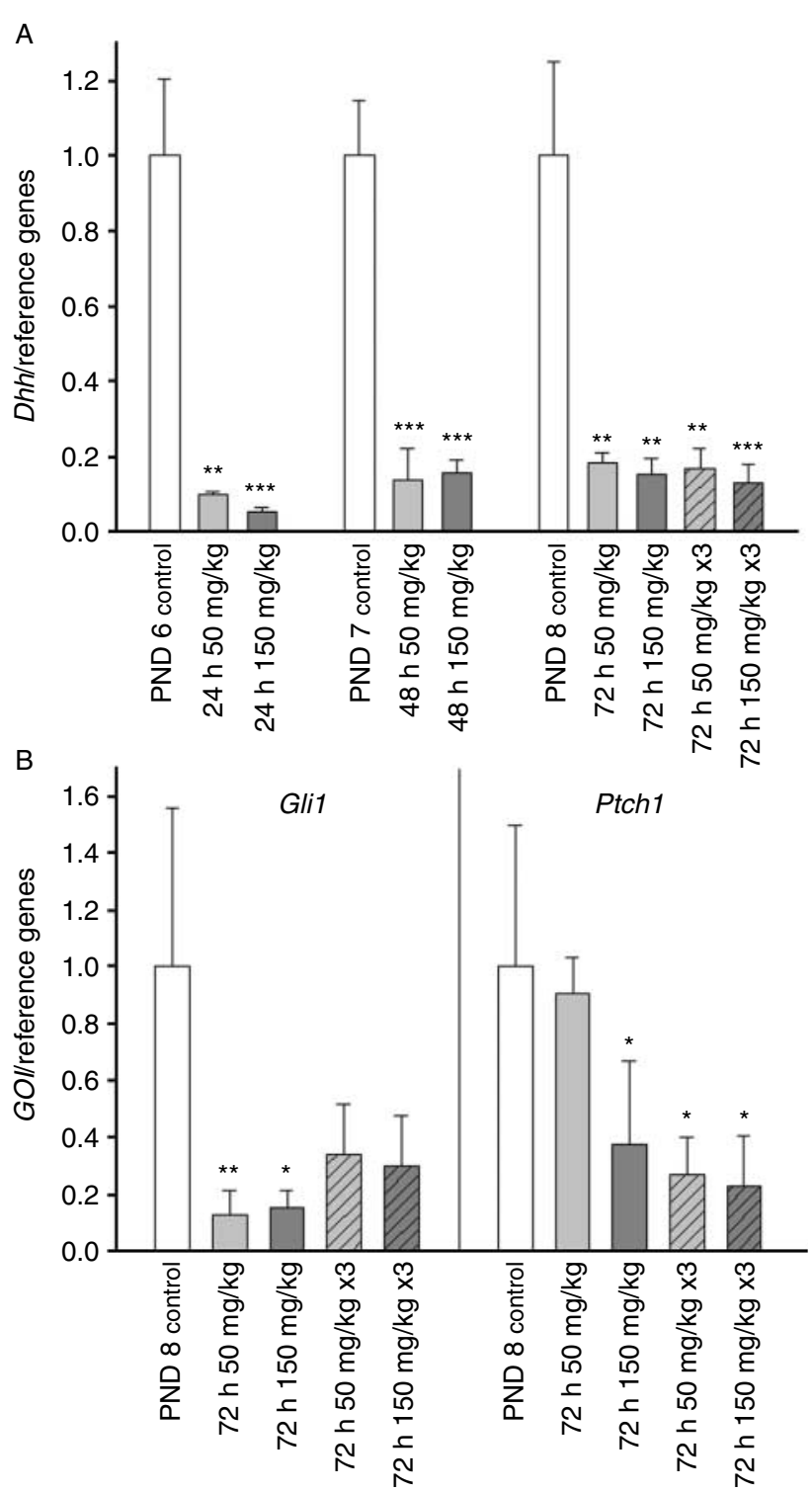

Figure 8 Imatinib mesylate-induced inhibition of tyrosine kinases impinges on Hedgehog signalling in prepubertal rat testis in vivo. (A) Imatinib treatment leads to down-regulated level of Dhh mRNA. (B) In response to reduced ligand production, a drop in Gli1 and Ptch1 mRNA levels is observed $72 \mathrm{~h}$ after the initial exposure. GOI, gene of interest; PND, postnatal day; $n=4$, S.E.M.; ${ }^{*} P<0.05 ;{ }^{*} P<0.01$; ***P<0.001.

(Carpenter et al. 1998). Morales et al. (2009) indicated that PTCH1 is expressed in late meiotic cells and postmeiotic cells of the mouse and rat testis. Our immunohistochemical staining showed that already early primary spermatocytes expressed PTCH1 but the signal from post-meiotic cells was weak and indistinguishable from the background. Taken together, these data suggest that PTCH1 may have a more important role in spermatogenesis than PTCH2.

Introduction of a $\mathrm{Hh}$ signalling inhibitor raises the number of cleaved caspase-3-positive germ cells markedly indicating that $\mathrm{Hh}$ signalling promotes germ cell survival. Since GLI1 and transcripts of Ptch2, Smo, Gli1, Gli2 and Gli3 (Szczepny et al. 2006) are expressed in spermatogonia and cyclopamine has been shown to impinge on Gli1 mRNA levels in vitro (Szczepny et al. 2009) these data suggest that Hh signalling is involved in the maintenance of spermatogonial cell population, such as GDNF (Meng et al. 2000). Intriguingly, both Gdnf and Dhh were down-regulated by FSH in vitro. In contrast, FSH elevated the mRNA levels of $S c f$, which is important for germ cell survival (Hakovirta et al. 1999, Yan et al. 2000b, 2000c). Intricate interaction between different growth and differentiation factors is needed to secure proper renewal of spermatogonial stem cells and differentiation of an appropriate number of spermatogonia further. Contradictory results have been presented about Gdnf regulation in the mouse testis (Tadokoro et al. 2002). Hh signalling can be one of the targets of environmental influence on testicular development as suggested by the effects of maternal smoking on the foetal testis (Fowler et al. 2008) and the impact of antiandrogen flutamide on rat foetal testis (Brokken et al. 2009). The effect of FSH on Sertoli cells is stimulatory and the number of FSH-induced transcripts is two- to sixfold higher than FSH-suppressed transcripts (McLean et al. 2002). The fact that FSH acts differentially on the steady-state levels of Dhh and Scf mRNAs which are at their highest in stages $\mathrm{II}-\mathrm{VI}$ of the rat seminiferous epithelial cycle and seem to share an anti-apoptotic function during spermatogenesis is intriguing. Despite having a seemingly similar effect on germ cells they might regulate different aspects of spermatogenesis and $\mathrm{FSH}$ is one of the factors that modulates this process.

We have previously reported that 3-day treatment of prepubertal male rats with imatinib on postnatal days 5-7 delayed the formation of germ-line stem cell pool, induced germ cell apoptosis, reduced proliferation of type A spermatogonia and peritubular myoid cells, and resulted in decreased testis weight due to disruption of longitudinal growth of the seminiferous tubules (Nurmio et al. 2007). Imatinib mesylate is a specific inhibitor of ABL, KIT, PDGFR and ARG tyrosine kinases (Druker et al. 1996, Nishimura et al. 2003) some of which have been proven to be activated by Sertoli cell-derived growth factors in the testis. In this study, imatinib mesylate strongly down-regulated Dhh mRNA levels in prepubertal rat testis. This can be explained by an imatinib mesylate-induced disturbance in the mechanism that normally sustain Dhh expression and demonstrates that the paracrine milieu affects the activity of $\mathrm{Hh}$ signalling in the rat testis. Imatinib-induced apoptosis might also contribute to the changes in Dhh, Ptch1 and Gli1 mRNA levels. However, since the incidence of apoptosis was not affected in a uniform way (Nurmio et al. 2007) after imatinib treatment but Dhh levels were, apoptosis cannot explain the changes alone. Interestingly, Szczepny et al. (2009) showed recently that inhibition of Hh signalling impinges on Scf and Kit mRNA levels 
in cultured mouse seminiferous tubules. Taken together, these data suggest that the testicular paracrine signalling network works interdependently and might collapse if even individual signalling pathways are disrupted.

In summary, we show here that $\mathrm{Hh}$ signalling is active in mitotic, meiotic and late post-meiotic cells of the rat seminiferous epithelium. Hh signalling is inhibited in early condensing spermatids. The steady-state levels of Hh pathway mRNAs are at their highest in stages II-VI of the rat seminiferous epithelial cycle. FSH and inhibition of RTK-dependent paracrine signalling pathways suppress $\mathrm{Hh}$ signalling by down-regulating ligand production in vitro and in vivo. In addition, Hh signalling has a physiological role in spermatogenesis in promoting germ cell survival.

\section{Materials and Methods}

\section{Animals, treatment and sample collection}

Male Sprague-Dawley rats at the ages of 1, 5, 10, 20, 30, 40 days and $2-4$ months were housed at the Animal Centre of Turku University (Turku, Finland) in an environment controlled for light (12 h light:12 h darkness), temperature $\left(21 \pm 3{ }^{\circ} \mathrm{C}\right)$ and air humidity $(55 \pm 15 \%)$ with free access to food (CRM diet; Special Diet Services, Witham, Essex, UK) and water. Turku University Committee on the Ethics of Animal Experimentation approved all animal experiments.

Five-day-old rats were treated with imatinib mesylate (STI571, Glivec; 50 or $150 \mathrm{mg} / \mathrm{kg}$; Novartis Pharma AG) dissolved in water and injected (injection volume $150 \mu \mathrm{l}$ ) intracavitally into the stomach as described previously (Nurmio et al. 2007) either once on fifth day of postnatal life or once every day on postnatal days 5-7. Control animals were injected in the same manner with water alone. The rats were killed by cervical dislocation under $\mathrm{CO}_{2}$ anaesthesia at $24(n=4), 48$ $(n=4)$ or $72(n=4)$ h after treatment or at specific ages mentioned above.

\section{Transillumination-assisted microdissection and culture of seminiferous tubules}

The testes were decapsulated on a Petri dish containing DMEM/Ham's Nutrient Mixture F-12 (1:1 DMEM/F12; Gibco BRL) supplemented with $0.1 \%(\mathrm{w} / \mathrm{v}) \mathrm{BSA}$, penicillin-streptomycin ( $50 \mathrm{U}$ and $50 \mu \mathrm{g} / \mathrm{ml}$, respectively; Gibco 15140) and gentamicin sulphate $(50 \mathrm{mg} / \mathrm{ml}$; Biowhittaker; Lonza, Walkersville, MD, USA). Using transillumination-assisted microdissection method (Parvinen \& Vanha-Perttula 1972, Toppari \& Parvinen 1985) 3-5 mm long segments of pooled stages II-VI, VII and VIII, IX-XII and XIII-I were dissected from five rats and used to study the stage-specific expression of $\mathrm{Hh}$ pathway genes. To study the endocrine regulation of gene expression in vitro six $2 \mathrm{~mm}$ long segments of stages II-VI, VII and VIII and IX-I from three rats were cultured in $1 \mathrm{ml}$ DMEM/F12 medium supplemented with $0.1 \%(\mathrm{w} / \mathrm{v}) \mathrm{BSA}$, penicillin-streptomycin ( $50 U$ and $50 \mu \mathrm{g} / \mathrm{ml}$, respectively; Gibco 15140), gentamicin sulphate $(50 \mathrm{mg} / \mathrm{ml}$; Biowhittaker; Lonza) and 1-methyl 3-isobutyl xanthine $(0.2 \mathrm{mmol} / \mathrm{l}$; Aldrich Chemie, Steinheim,
Germany) in the presence of recombinant human FSH (Gonal F, Serono). Doses of 1, 10, 25, 50 and $200 \mathrm{ng} / \mathrm{ml}$ of rhFSH were used to study responsiveness of Dhh, Scf and Gdnf mRNA expression. Within individual experiments each dose was applied on three parallel samples. After 8 and $30 \mathrm{~h}$ incubation $\left(34{ }^{\circ} \mathrm{C}, 5 \% \mathrm{CO}_{2}\right.$, humidified atmosphere) the cultured segments of rat seminiferous tubules were collected and snap-frozen in liquid nitrogen.

\section{RNA isolation and CDNA synthesis}

Total RNA from freshly collected or cultured segments of rat seminiferous tubules was isolated using Trisure reagent (Bioline, London, UK) according to the manufacturer's instructions. Testicular tissue samples were homogenised with a disperser (UltraTurrax; IKA Werke GmbH \& Co. KG, Staufen, Germany) in $600 \mu \mathrm{l}$ RLT buffer (from the Qiagen RNeasy Mini Kit; Qiagen) supplemented with $6 \mu \mathrm{l} \beta$-mercaptoethanol. Thereafter, total RNA was extracted using Qiagen RNeasy Mini Kit according to the manufacturer's instructions. After isolation, RNA concentration was measured using NanoDrop device (ND-1000; NanoDrop Technologies, Wilmington, DE, USA). RNA quality was assessed visually by confirmation of intact $28 \mathrm{~S}$ and $18 \mathrm{~S}$ ribosomal bands following agarose gel electrophoresis and ethidium bromide staining. Before cDNA synthesis traces of contaminating genomic DNA were removed by treating samples with DNase I (Invitrogen). cDNA was synthesised using DyNAmo SYBR Green 2-step qRT-PCR Kit (Finnzymes, Espoo, Finland); $500 \mathrm{ng}$ of template RNA was reverse transcribed in a $20 \mu \mathrm{l}$ reaction with oligo(dT) primers. DNase I-treated samples were split to two and one half was used for cDNA synthesis while the other served as a template in RT reaction.

\section{Real-time PCR}

Primer pairs were designed to be located to different exonic sequences using freely online available Primer 3 software (http://frodo.wi.mit.edu/) and gene sequences available at $\mathrm{NCBI}$ and Ensembl databases (Table 1). PCR amplification was performed by MJ Research Chromo4 thermocycler (BioRad Laboratories, Inc.) and the DyNAmo SYBR Green 2-step qRT-PCR Kit (Finnzymes) according to the manufacturer's instructions. PCRs for detection of the endogenous control genes, glyceraldehyde-3-phosphate dehydrogenase (Gapdh), hypoxanthine phosphoribosyltransferase 1 (Hprt1) and S26 ribosomal protein (S26), were run for each cDNA template. Quantitative real-time PCR was performed under the following conditions: $95^{\circ} \mathrm{C}$ for 15 min followed by 40 cycles of $94{ }^{\circ} \mathrm{C}$ for $10 \mathrm{~s}, 54-64{ }^{\circ} \mathrm{C}$ (depending on the primer pair; see Table 1) for $30 \mathrm{~s}$, and $72{ }^{\circ} \mathrm{C}$ for $30 \mathrm{~s}$. Melting curve analysis was carried out immediately following amplification by increasing the temperature in $0.5^{\circ} \mathrm{C}$ increments starting at $72{ }^{\circ} \mathrm{C}$ for 45 cycles of $1 \mathrm{~s}$ each. The specificity of PCR was verified both by the presence of a single melting temperature and by detection of a single band of the expected size on agarose gel. Relative gene expression data was quantified using the $2^{-\Delta \Delta C_{\mathrm{T}}}$ method (Livak \& Schmittgen 2001). 
Table 1 Primer design, annealing temperatures and PCR product lengths of the studied rat mRNAs.

\begin{tabular}{|c|c|c|c|c|}
\hline Gene & Accession number & Annealing temperature $\left({ }^{\circ} \mathrm{C}\right)$ & Primers & Product length $(b p)$ \\
\hline Dhh & AF148226 & 64 & $\begin{array}{l}5^{\prime} \text {-GACCTCGTCCCCAACTACAA-3' } \\
5^{\prime} \text {-AACCTTCAGTCACGCGTAGG-3' }\end{array}$ & 159 \\
\hline Ptch1 & NM_053566 & 58 & $\begin{array}{l}5^{\prime} \text {-GGCTGAGAGCGAAGTTTCAA-3' } \\
5^{\prime} \text {-GCCTCTGTGGTCAGGACATT-3' }\end{array}$ & 271 \\
\hline Ptch2 & NM_01108975 & 63 & $\begin{array}{l}5^{\prime} \text {-CCAGGAACCTCTGGATTTCA-3' } \\
5^{\prime} \text {-GATGCGAAGGTTCTCTCCAG-3' }\end{array}$ & 207 \\
\hline Gli1 & XM_345832 & 63 & $\begin{array}{l}5^{\prime} \text {-GGTTATGGGTCTGCCAGAGA-3' } \\
5^{\prime} \text {-GCTGGGTGAGGTACGGATTA-3' }\end{array}$ & 159 \\
\hline Gli2 & NM_001107169 & 60 & $\begin{array}{l}5^{\prime} \text {-TACGAGACCAACTGCCACTG-3' } \\
5^{\prime} \text {-CCTTTGAGCAGCCTTCAAAC-3 } 3^{\prime}\end{array}$ & 235 \\
\hline Gli3 & XM_225411 & 59 & $\begin{array}{l}\text { 5'-TTCTGAACCСТGTCCAGGTC-3' } \\
5^{\prime} \text {-TCTTTGTCСССТTCСТССТT-3' }\end{array}$ & 207 \\
\hline Sufu & NM_001024899 & 60 & $\begin{array}{l}5^{\prime} \text {-GGTCCCTGGCTGATAACTGA-3' } \\
5^{\prime} \text {-GTCTTTGCCAGACAGCCTTC-3' }\end{array}$ & 224 \\
\hline Ihh & NM_053384 & 60 & $\begin{array}{l}5^{\prime} \text {-GACCGCGACCGAAATAAGTA-3' } \\
5^{\prime} \text {-ACGCTCCCCAGTTTCTAGGT-3' }\end{array}$ & 182 \\
\hline Shh & NM_017221 & 60 & $\begin{array}{l}\text { 5'-GGAACTCACCCCCAATTACA-3' } \\
5^{\prime} \text {-TCACTCGAAGCTTCACTCCA-3' }\end{array}$ & 151 \\
\hline Fshr & NM_199237 & 56 & $\begin{array}{l}5^{\prime} \text {-СCTCTGGGCCAGTCATTTTA-3' } \\
5^{\prime} \text {-GTTCAGAGATTTGCCGCTTC-3' }\end{array}$ & 213 \\
\hline Scf & $\begin{array}{l}\text { NM_021843 } \\
\text { NM_021844 }\end{array}$ & 61 & $\begin{array}{l}\text { 5'-CAAAACTGGTGGCGAATCTT-3' } \\
5^{\prime} \text {-GCCACGAGGTCATCCACTAT-3' }\end{array}$ & 218 \\
\hline Gdnf & NM_019139 & 61 & $\begin{array}{l}5^{\prime} \text {-CGGACGGGACTCTAAGATGA-3' } \\
5^{\prime} \text {-CGTCATCAAACTGGTCAGGA-3' }\end{array}$ & 205 \\
\hline Gapdh & NM_017008 & 55 & $\begin{array}{l}5^{\prime} \text {-AGACAGCCGCATCTTCTTGT-3' } \\
5^{\prime} \text {-CTTGCCGTGGGTAGAGTCAT-3' }\end{array}$ & 207 \\
\hline Hprt1 & NM_012583 & 54 & $\begin{array}{l}\text { 5'-AAGCTTGCTGGTGAAAAGGA-3' } \\
5^{\prime} \text {-CCGCTGTCTTTTAGGCTTTG-3' }\end{array}$ & 185 \\
\hline$S 26$ & XM_001066146 & 57 & $\begin{array}{l}\text { 5'-AAGGAGAAACAACGGTCGTG-3' } \\
5^{\prime} \text {-GCAGGTCTGAATCGTGGTG-3' }\end{array}$ & 300 \\
\hline
\end{tabular}

Dhh, desert hedgehog; Ptch, patched; Gli1, glioma-associated oncogene homologue; Sufu, suppressor of fused; Ihh, Indian hedgehog; Shh, sonic hedgehog; Fshr, FSH receptor; Gdnf, glial cell line-derived neurotrophic factor; Scf, stem cell factor; Gapdh, glyceraldehyde-3-phosphate dehydrogenase; Hprt1, hypoxanthine phosphoribosyltransferase 1; S26, S26 ribosomal protein.

\section{Squash preparations}

Segments (4 mm long) of stages II-VI of the rat seminiferous epithelial cycle from four rats were incubated 8 and $16 \mathrm{~h}$ in the medium and conditions mentioned above in the presence of $100 \mu \mathrm{mol} / \mathrm{l}$ cyclopamine (LC Laboratories, Woburn, MA, USA) or vehicle only. After the incubation the segments were transferred to a Petri dish and cut to $2 \mathrm{~mm}$ of length under a stereomicroscope by taking $\sim 1 \mathrm{~mm}$ off from both ends. Squash preparations were made as described by Toppari et al. (1985). Briefly, the segments were taken in $15 \mu \mathrm{l}$ PBS ( $\mathrm{pH}$ 7.4) onto a microscope slide. The tubule segments were carefully squashed between microscope slides and cover slips and the formation of a cellular monolayer was monitored by phase contrast microscopy. Then the squash preparations were snapfrozen in liquid nitrogen and the cover slips were removed. The slides were incubated in ice-cold 96\% (v/v) ethanol for $3 \mathrm{~min}$ and allowed to air-dry overnight.

\section{Immunohistochemical staining of Hh pathway components}

Rat testes were fixed in $4 \%(\mathrm{v} / \mathrm{v})$ paraformaldehyde at $+4{ }^{\circ} \mathrm{C}$ overnight. The fixed samples were dehydrated by using graded ethanol solutions and stored in $70 \%(\mathrm{v} / \mathrm{v})$ ethanol at $+4{ }^{\circ} \mathrm{C}$. After paraffin embedding $5 \mu \mathrm{m}$ thick sections were cut and mounted onto poly-lysine-coated slides. Following rehydration the slides were washed once in PBS and twice in PBS $+0.2 \%$ $(\mathrm{v} / \mathrm{v})$ Triton X-100 for $5 \mathrm{~min}$ each. Antigen retrieval was performed by microwaving $(300 \mathrm{~W})$ the slides for $15 \mathrm{~min}$ in sodium citrate buffer $(10 \mathrm{mmol} / \mathrm{l}, \mathrm{pH}$ 6.0). After washing for $5 \mathrm{~min}$ in PBS $+0.2 \%(\mathrm{v} / \mathrm{v})$ Triton X-100 two times, autofluorescence was quenched by treating the slides with $100 \mathrm{mM}$ $\mathrm{NHCl}_{4}$ for $3 \mathrm{~min}$. Following washes twice with PBS $+0.2 \%$ $(\mathrm{v} / \mathrm{v})$ Triton X-100 and once with PBS, blocking solution $(20 \%$ $(\mathrm{v} / \mathrm{v})$ normal goat serum or $20 \%(\mathrm{v} / \mathrm{v}) \mathrm{BSA}$ in PBS $+0.2 \%(\mathrm{v} / \mathrm{v})$ Triton X-100 for sections that are later incubated with goat or donkey secondary antibodies, respectively) was applied to each section and incubated $1 \mathrm{~h}$ at RT. After blocking, sections were incubated overnight at $+4{ }^{\circ} \mathrm{C}$ in the presence of an aliquot of $100 \mu \mathrm{l}$ primary antibody (diluted 1:50 in PBS $+0.2 \%$ $(\mathrm{v} / \mathrm{v})$ Triton X-100+1.5\% (v/v) NGS or BSA; see above). Primary antibodies used were: goat polyclonal anti-PTCH1 (sc-6149; Santa Cruz Biotechnology, Inc., Santa Cruz, CA, USA), rabbit polyclonal anti-GLI1 (sc-20687, Santa Cruz Biotechnology, Inc.) and goat polyclonal anti-SUFU (sc10933, Santa Cruz Biotechnology, Inc.). Primary antibody incubation was omitted in negative controls.

Secondary antibodies used were Texas Red-conjugated donkey anti-goat (sc-2783, Santa Cruz Biotechnology, Inc.) and Alexa Fluor 594-conjugated anti-rabbit antibody (A11037, Invitrogen). After $1 \mathrm{~h}$ secondary antibody incubation the slides were washed three times with PBS and mounted with UltraCruz mounting medium (sc-24941, Santa Cruz 
Biotechnology, Inc.). Images were captured using a Leica DFC320 camera (Leica, Wetzlar, Germany) installed on a DMRBE microscope from the same manufacturer. Four histological sections from at least three different animals were included in all IHC analyses.

\section{Immunocytochemical staining of cleaved caspase-3 on the squash preparations}

Air-dried squash preparations were stored at $-80{ }^{\circ} \mathrm{C}$ and fixed in $4 \%(\mathrm{v} / \mathrm{v})$ paraformaldehyde for $10 \mathrm{~min}$. After fixation they were washed twice with Tris-buffered saline (TBS, $\mathrm{pH}$ 7.55) for $5 \mathrm{~min}$ and antibody penetration was improved by incubating the slides $10 \mathrm{~min}$ in TBS $+0.2 \%(\mathrm{v} / \mathrm{v})$ Triton $\mathrm{X}-100$. From this step on cleaved caspase-3 staining was performed by Novocastra Novolink Polymer Detection Systems (Leica Microsystems, Inc., Bannockburn, IL, USA) according to the manufacturer's instructions. Cleaved caspase-3 primary antibody was purchased from Cell Signalling Technology (Asp175, Beverly, MA, USA) and used at dilution of 1:200.

\section{Statistical analysis}

The results were analysed for statistically significant differences using ANOVA, followed by Tukey's test for multiple comparisons of independent groups of samples. Student's $t$-test was used for pairwise comparison. The $P$ values $<0.05$ were considered statistically significant.

\section{Declaration of interest}

The authors declare that there is no conflict of interest that could be perceived as prejudicing the impartiality of the research reported.

\section{Funding}

This work was supported by the Sigrid Jusélius foundation, Academy of Finland, Turku University Hospital and Turku Graduate School of Biomedical Sciences (TuBS).

\section{Acknowledgements}

We thank Mrs Taija Leinonen for her skilful technical assistance.

\section{References}

Barsoum IB, Bingham NC, Parker KL, Jorgensen JS \& Yao HH 2009 Activation of the Hedgehog pathway in the mouse fetal ovary leads to ectopic appearance of fetal Leydig cells and female pseudohermaphroditism. Developmental Biology 329 96-103. (doi:10.1016/j.ydbio.2009. 02.025)

Bitgood MJ, Shen L \& McMahon AP 1996 Sertoli cell signaling by desert hedgehog regulates the male germline. Current Biology 6 298-304. (doi:10.1016/S0960-9822(02)00480-3)
Brokken LJ, Adamsson A, Paranko J \& Toppari J 2009 Antiandrogen exposure in utero disrupts expression of desert hedgehog and insulin-like factor 3 in the developing fetal rat testis. Endocrinology 150 445-451. (doi:10.1210/en.2008-0230)

Carpenter D, Stone DM, Brush J, Ryan A, Armanini M, Frantz G, Rosenthal A \& de Sauvage FJ 1998 Characterization of two patched receptors for the vertebrate hedgehog protein family. PNAS 95 13630-13634. (doi:10.1073/pnas.95.23.13630)

Clark AM, Garland KK \& Russell LD 2000 Desert hedgehog (Dhh) gene is required in the mouse testis for formation of adult-type Leydig cells and normal development of peritubular cells and seminiferous tubules. Biology of Reproduction 63 1825-1838. (doi:10.1095/biolreprod63.6. 1825)

Clermont Y \& Perey B 1957 Quantitative study of the cell population of the seminiferous tubules in immature rats. American Journal of Anatomy $\mathbf{1 0 0}$ 241-267. (doi:10.1002/aja.1001000205)

Druker BJ, Tamura S, Buchdunger E, Ohno S, Segal GM, Fanning S, Zimmermann J \& Lydon NB 1996 Effects of a selective inhibitor of the Abl tyrosine kinase on the growth of Bcr-Abl positive cells. Nature Medicine 2 561-566. (doi:10.1038/nm0596-561)

Fowler PA, Cassie S, Rhind SM, Brewer MJ, Collinson JM, Lea RG, Baker PJ, Bhattacharya S \& O'Shaughnessy PJ 2008 Maternal smoking during pregnancy specifically reduces human fetal desert hedgehog gene expression during testis development. Journal of Clinical Endocrinology and Metabolism 93 619-626. (doi:10.1210/jc.2007-1860)

Hakovirta H, Yan W, Kaleva M, Zhang F, Vänttinen K, Morris PL, Söder M, Parvinen M \& Toppari J 1999 Function of stem cell factor as a survival factor of spermatogonia and localization of messenger ribonucleic acid in the rat seminiferous epithelium. Endocrinology 140 1492-1498. (doi:10.1210/en.140.3.1492)

Heckert LL \& Griswold MD 1991 Expression of follicle-stimulating hormone receptor mRNA in rat testes and Sertoli cells. Molecular Endocrinology 5 670-677. (doi:10.1210/mend-5-5-670)

Hooper JE \& Scott MP 1989 The Drosophila patched gene encodes a putative membrane protein required for segmental patterning. Cell $\mathbf{5 9}$ 751-765. (doi:10.1016/0092-8674(89)90021-4)

Kogerman P, Grimm T, Kogerman L, Krause D, Unden AB, Sandstedt B, Toftgard R \& Zaphiropoulos PG 1999 Mammalian suppressor-of-fused modulates nuclear-cytoplasmic shuttling of Gli-1. Nature Cell Biology $\mathbf{1}$ 312-319. (doi:10.1038/13031)

Kroft TL, Patterson J, Won Yoon J, Doglio L, Walterhouse DO, lannaccone PM \& Goldberg E 2001 GLI1 localization in the germinal epithelial cells alternates between cytoplasm and nucleus: upregulation in transgenic mice blocks spermatogenesis in pachytene. Biology of Reproduction 65 1663-1671. (doi:10.1095/biolreprod65.6.1663)

Lauth M \& Toftgård R 2007 Non-canonical activation of GLI transcription factors: implications for targeted anti-cancer therapy. Cell Cycle 6 2458-2463. (doi:10.4161/cc.6.20.4808)

Leblond CP \& Clermont Y 1952 Definition of the stages of the cycle of the seminiferous epithelium in the rat. Annals of the New York Academy of Sciences 55 548-573. (doi:10.1111/j.1749-6632.1952.tb26576.x)

Lee J, Platt KA, Censullo P \& Ruiz i Altaba A 1997 Gli1 is a target of Sonic hedgehog that induces ventral neural tube development. Development 124 2537-2552.

Livak KJ \& Schmittgen TD 2001 Analysis of relative gene expression data using real-time quantitative PCR and the $2(-$ Delta Delta $C(T))$ method. Methods 25 402-408. (doi:10.1006/meth.2001.1262)

Malkov M, Fisher Y \& Don J 1998 Development schedule of the postnatal rat testis determined by flow cytometry. Biology of Reproduction 59 84-92. (doi:10.1095/biolreprod59.1.84)

McLean DJ, Friel PJ, Pouchnik D \& Griswold MD 2002 Oligonucleotide microarray analysis of gene expression in follicle-stimulating hormonetreated rat Sertoli cells. Molecular Endocrinology 16 2780-2792. (doi:10.1210/me.2002-0059)

Meng X, Lindahl M, Hyvonen ME, Parvinen M, de Rooij DG, Hess MW, Raatikainen-Ahokas A, Sainio K, Rauvala H, Lakso M et al. 2000 Regulation of cell fate decision of undifferentiated spermatogonia by GDNF. Science 287 1489-1493. (doi:10.1126/science.287.5457.1489)

Morales CR, Fox A, El-Alfy M, Ni X \& Argraves WS 2009 Expression of patched-1 and smoothened in testicular meiotic and post-meiotic cells. Microscopy Research and Technique 72 809-815. (doi:10.1002/jemt. 20733) 
Nishimura N, Furukawa Y, Sutheesophon K, Nakamura M, Kishi K Okuda K, Sato Y \& Kano Y 2003 Suppression of ARG kinase activity by STI571 induces cell cycle arrest through up-regulation of CDK inhibitor p18/INK4c. Oncogene 22 4074-4082. (doi:10.1038/sj.onc.1206498)

Nurmio M, Toppari J, Zaman F, Andersson AM, Paranko J, Söder O \& Jahnukainen K 2007 Inhibition of tyrosine kinases PDGFR and C-Kit by imatinib mesylate interferes with postnatal testicular development in the rat. International Journal of Andrology 30 366-376. (doi:10.1111/j.13652605.2007.00755.x)

Parvinen M \& Vanha-Perttula T 1972 Identification and enzyme quantitation of the stages of the seminiferous epithelial wave in the rat. Anatomical Record 174 435-449. (doi:10.1002/ar.1091740404)

Pierucci-Alves F, Clark AM \& Russell LD 2001 A developmental study of the desert hedgehog-null mouse testis. Biology of Reproduction 65 1392-1402. (doi:10.1095/biolreprod65.5.1392)

Riobo NA, Lu K \& Emerson CP Jr 2006 Hedgehog signal transduction: signal integration and cross talk in development and cancer. Cell Cycle 5 1612-1615. (doi:10.4161/cc.5.15.3130)

Szczepny A, Hime GR \& Loveland KL 2006 Expression of hedgehog signaling components in adult mouse testis. Developmental Dynamics 235 3063-3070. (doi:10.1002/dvdy.20931)

Szczepny A, Hogarth CA, Young J \& Loveland KL 2009 Identification of Hedgehog signaling outcomes in mouse testis development using a hanging drop-culture system. Biology of Reproduction 80 258-263. (doi:10.1095/biolreprod.108.067926)

Tadokoro Y, Yomogida K, Ohta H, Tohda A \& Nishimune Y 2002 Homeostatic regulation of germinal stem cell proliferation by the GDNF/FSH pathway. Mechanisms of Development 113 29-39. (doi:10.1016/S0925-4773(02)00004-7)

Taipale J, Cooper MK, Maiti T \& Beachy PA 2002 Patched acts catalytically to suppress the activity of Smoothened. Nature 418 892-897. (doi:10. 1038/nature00989)

Toppari J \& Parvinen M 1985 In vitro differentiation of rat seminiferous tubular segments from defined stages of the epithelial cycle: morphologic and immunolocalization analysis. Journal of Andrology 6 334-343.
Toppari J, Eerola E \& Parvinen M 1985 Flow cytometric DNA analysis of defined stages of rat seminiferous epithelial cycle during in vitro differentiation. Journal of Andrology 6 325-333.

Yan W, Linderborg J, Suominen J \& Toppari J 1999 Stage-specific regulation of stem cell factor gene expression in the rat seminiferous epithelium. Endocrinology 140 1499-1504. (doi:10.1210/en.140.3.1499)

Yan W, Samson M, Jégou B \& Toppari J 2000a Bcl-w forms complexes with $\mathrm{Bax}$ and Bak, and elevated ratios of $\mathrm{Bax} / \mathrm{BCl}-\mathrm{w}$ and $\mathrm{Bak} / \mathrm{BCl}-\mathrm{w}$ correspond to spermatogonial and spermatocyte apoptosis in the testis. Molecular Endocrinology 14 682-699. (doi:10.1210/me.14.5.682)

Yan W, Suominen J, Samson M, Jégou B \& Toppari J $2000 \mathrm{~b}$ Involvement of $\mathrm{BCl}-2$ family proteins in germ cell apoptosis during testicular development in the rat and pro-survival effect of stem cell factor on germ cells in vitro. Molecular and Cellular Endocrinology 165 115-129. (doi:10. 1016/S0303-7207(00)00257-4)

Yan W, Suominen J \& Toppari J 2000c Stem cell factor protects germ cells from apoptosis in vitro. Journal of Cell Science 113 161-168.

Yao HH \& Capel B 2002 Disruption of testis cords by cyclopamine or forskolin reveals independent cellular pathways in testis organogenesis. Developmental Biology 246 356-365. (doi:10.1006/dbio.2002.0663)

Yao HH, Whoriskey W \& Capel B 2002 Desert Hedgehog/Patched 1 signaling specifies fetal Leydig cell fate in testis organogenesis. Genes and Development 16 1433-1440. (doi:10.1101/gad.981202)

Yoshinaga K, Nishikawa S, Ogawa M, Hayashi S, Kunisada T, Fujimoto T \& Nishikawa S 1991 Role of c-kit in mouse spermatogenesis: identification of spermatogonia as a specific site of c-kit expression and function. Development 113 689-699.

Received 11 April 2011

First decision 9 May 2011

Revised manuscript received 25 August 2011

Accepted 5 September 2011 